\title{
EDUCAÇÃO PENITENCIÁRIA E EDUCAÇÃO ESPECIAL: APROXIMANDO ÁREAS DE PESQUISA ${ }^{1}$
}

\author{
Margarete Rodrigues de Lima \\ Almiro Alves de Abreu \\ Leila do Socorro Rodrigues Feio
}

\section{INTRODUÇÃO}

O tema desta pesquisa foi o atendimento educacional especializado (AEE) aos estudantes com deficiência, que estavam matriculados na Escola Estadual São José (EESJ), localizada dentro do Instituto de Administração Penitenciária do Amapá (IAPEN), assunto que envolve os professores da Educação Especial que trabalham no ambiente carcerário.

$\mathrm{O}$ artigo foi produzido, com base nas seguintes inquietações: A EESJ tem no seu corpo docente, profissionais da educação especial? Quais estudantes são atendidos pelos professores do AEE? Há dificuldade na aplicação da metodologia do AEE? Existe diferença entre a metodologia da escola da EJA fora da prisão em relação à EESJ?

A EESJ situa-se dentro de uma penitenciária e os professores/estudantes enfrentam os problemas relacionados à rotina do cárcere, o que dificulta a formação escolar aos adultos presos. Outras dificuldades foram percebidas com base na visita realizada na escola, como sua pequena estrutura física, pois ela foi planejada para atender poucas turmas. Além disso, o currículo escolar é dissociado da vida carcerária e os professores da educação especial não têm sala multifuncional para realizar os serviços do AEE.

Se os problemas mencionados forem negligenciados pelo Estado, a Educação de Jovens e Adultos na Educação Penitenciária pode tornar-se inócua, uma vez que pode levar o retorno do adulto preso com deficiência e o egresso do sistema penitenciário à sociedade amapaense, sem ter acesso aos serviços do AEE.

${ }^{1}$ DOI: $10.29388 / 978-65-86678-21-5-f .79-100$. 


\section{EDUCAÇÃO PENITENCIÁRIA NO BRASIL}

Com a outorgação da Constituição Política do Império do Brasil, reconheceu-se que o governo era monárquico hereditário, constitucional e representativo. No que se refere à construção das casas de prisão, trabalho, correção e seus regimes, eram as assembleias legislativas que deviam legislar sobre esse assunto. Também foram abolidas as penas de açoites, a marca de ferro, a tortuna, entre outras penas cruéis e regulamentou-se que cadeias deveriam ser seguras, limpas e arejadas para separar os réus, de acordo com suas circunstâncias e natureza dos crimes (BRASIL, 1824).

Dropa (2001) analisa que como reforço à Constituição de 1824, elaborou-se o Código Criminal de 1830, que normatizou a pena de trabalho e a prisão simples no Brasil. Além disso, o Ato Adicional de 12 de agosto de 1834, atribuiu às Assembleias Legislativas das Províncias o dever, quanto à construção das casas de prisão, trabalho e correção. Ainda o autor enfatiza que o mesmo não acontecia com as casas de recolhimento de presos do início do século XIX, pois eram insalubres para execução das penas.

O nascimento da prisão e sua relação com a sociedade disciplinar, as técnicas penitenciárias e seus princípios, isto é, a correção, classificação do condenado, modulação das penas, trabalho como obrigação ou direito, educação penitenciária, controle técnico da detenção e instituições anexas, é uma discussão apresentada por Foucault (1977). O filósofo explica entre os séculos XVIII e XIX, que a prisão como instituição, surgiu para executar a pena privativa de liberdade. E portanto, para que o corpo do condenado fosse educado e reeducado, seu tempo deveria ser medido e utilizado, bem como suas forças deveriam destinarem-se ao trabalho.

A palavra "educação penitenciária" aparece no livro Vigiar e Punir: Nascimento da prisão de Foucault (1977) como parte do assunto estudado por ele. Esse estudo centrou-se nas formas de controle do homem e considerando o seu corpo e alma, o que envolve a prisão, a fábrica, a escola, o hospital e outras instituições que se espalharam em distintas sociedades.

As construções das prisões entre os séculos XVIII e XIX, relacionamse com o desenvolvimento dos sistemas penitenciários nos Estados Unidos e Europa, como o sistema celular, auburniano e progressivo. Quanto a esse aspecto, conhecer sobre suas características permite compreender de que forma a instrução religiosa, moral e escolar foram inseridas no regime penitenciário.

Vejamos um comentário a esse respeito, segundo Carvalho Filho (2002): 
Estamos nos referindo ao Sistema Celular instituído na Filadélfia em 1790 que impunha aos condenados isolamento na cela 24 horas por dia, com pretensão de estimular o arrependimento, a meditação e a oração com a prática da leitura da bíblia; Sistema Auburniano adotado a partir de 1820 em Nova York que aplicava aos condenados isolamento celular noturno, mas com trabalho diurno e refeições em comum; e o Sistema Progressivo que parece ter sido implantado no presídio na ilha Norfolk entre a Nova Zelândia e a Nova Caledônia que adotou a concessão de benefícios ao preso considerando o bom comportamento carcerário e o trabalho realizado por ele, visando seu retorno ao convívio social (apud VASQUEZ, 2015, p. 31).

A autora faz essa ponderação para indicar algumas características de três modelos de sistemas penitenciários que existiram antes da construção das prisões no Brasil Império e que exerceram influência nas discussões sobre como deveria ocorrer a execução das penas.

A instrução religiosa, moral e escolar na segunda metade do Brasil Império fazia parte das normas dos regulamentos penitenciários, o que verificamos em documentos da Casa de Correções do Rio de Janeiro, nas Casas de Correções de São Paulo e Porto Alegre, do Presídio de Fernando de Noronha e da Colônia Correcional de Dois Reis, já no início do século XX. Estes regulamentavam o ensino carcerário, os deveres dos empregados, como também definiam seu programa curricular, as penas disciplinares, entre outras regras (VASQUEZ, 2015).

Além da autora analisar documentos de prisões do Brasil do período imperial, também estudou a Lei $n^{\circ} 3274 / 57$, que instituiu as Normas Gerais do Regime Penitenciário e a Lei $n^{\circ} 7210 / 84$, que regulamentou as regras para execução penal, o que a levou a constatar que a educação penitenciária foi defendida em regulamentos das prisões da segunda metade do século XIX e ocorreu de forma lenta, concomitante ao desenvolvimento da instrução pública.

Quanto à educação penitenciária no Amapá, seu estudo enfocou de 1975 a 2007 e documentou que foram implantados programas educacionais pelo Governo Federal, como o Projeto Minerva e Projeto João da Silva, respectivamente, pelo ensino por meio do rádio, cursos ofertados nos telepostos e turmas de ensino personalizado para adultos presos. E também oferta de curso de ensino fundamental e médio pela modalidade Educação de Jovens e Adultos para turmas de $1^{\mathrm{a}}, 2^{\mathrm{a}}, 3^{\mathrm{a}}$ e $4^{\mathrm{a}}$ etapas, o que caracteriza a cultura escolar, mas os adultos presos vivenciam no seu cotidiano, a cultura prisional (VASQUEZ, 2015). 
Seguindo outra perspectiva de análise em relação à educação penitenciária no Amapá, Abreu (2008) estudou a temática, enfatizando-a como discussão relacionada à Educação de Jovens e Adultos no Brasil. Ele evidenciou o currículo das turmas de $1^{\mathrm{a}}, 2^{\mathrm{a}}, 3^{\mathrm{a}}$ e $4^{\mathrm{a}}$ quartas etapas da EESJ e o trabalho desenvolvido pelos professores da rede pública estadual de ensino de Ciências Humanas, da Natureza, Matemática e suas Tecnologias, Linguagens e Códigos, na única escola instalada no sistema penitenciário amapaense, em 2008, os quais são servidores públicos lotados na Secretaria de Estado da Educação (SEED/ $\mathrm{AP})$.

Há de se considerar que de 1984 até 2015, a legislação brasileira que trata sobre a educação e que se aplica à população carcerária foi ampliada, aqui nos referimos à Constituição Federal - CF, à Lei de Diretrizes e Bases da Educação Nacional - LDBN, à Lei de Execução Penal - LEP. Além da legislação mais recente, como a Lei que instituiu o Plano Estratégico de Educação no âmbito do Sistema Prisional, e ainda outra que alterou artigos da LEP, no que se refere à assistência educacional e que reconheceu a obrigação dos Estados de ofertar curso de ensino médio nas penitenciárias (BRASIL, 1984; 1988; 2011, 2015; GOMES, 2006).

É inegável que a legislação brasileira defende o direito à educação para pessoas que estão custodiadas nas prisões. Entretanto, a educação penitenciária ainda não é uma modalidade de ensino no Brasil, mesmo existindo uma comunidade de profissionais da educação que trabalham com a oferta de cursos de educação formal nas escolas que estão dentro ou perto das prisões.

Por outro lado, em países como Argentina e Estados Unidos, as demandas da educação em contexto de confinamento são reconhecidas suas especificidades, através da Educação em Contextos de Privação de Liberdade e Educação Correcional (ARGENTINA, 2006; MESSEMER, 2011), o que envolve programas educacionais à população carcerária e aos jovens infratores.

Já no Brasil, essas comunidades de estudantes são atendidas apenas pela Educação de Jovens e Adultos, pois o Art. 37 da LDBN normatizou que essa modalidade destina-se "àqueles que não tiveram acesso ou oportunidade de estudos no ensino fundamental e médio na idade própria” (BRASIL, 1996).

\section{EDUCAÇÃO ESPECIAL NO BRASIL}

A luta da pessoa com deficiência no Brasil, segundo Mantoan (2004) possui três marcos distintos, que se destacam nesse processo histórico: Segregação, integração e inclusão. Na antiguidade, por volta do século VIII a.C., as cri- 
anças que nasciam com algum problema físico ou mental eram exterminadas ou eram deixadas à própria sorte. Esse período ficou conhecido como segregação, pois excluía totalmente a pessoa com deficiência dos seus direitos e especialmente o direito à educação.

Um segundo momento histórico foi no século XIX, que ficou denominado de integração. A integração veio com o advento do Cristianismo, período em que a Igreja Católica para praticar a caridade, acolhia crianças com alguma deficiência. Essa forma bondosa da Igreja que agia de um jeito mais "humano", também pregava que aquele que nascia com alguma anomalia estava sendo castigado por Deus, porque seus pais eram pecadores. Portanto, ter um filho com deficiência nessa época era motivo de vergonha perante a sociedade.

O período que conhecemos hoje e chamamos de inclusão, começou a se difundir em meados da década de 1980, quando a Organização das Nações Unidas - ONU, reuniu em um congresso em Nova York, vários grupos de pessoas com deficiência e foi aprovado que a década de 1980, seria de luta da pessoa com deficiência, ao mesmo tempo escolheram o dia 21 de setembro, como o dia mundial de luta dessas pessoas.

Mesmo o Brasil sendo signatário do documento de Nova York, o Governo Brasileiro não tomou nenhuma providência imediata para aplicá-lo nas ações da política educacional, o que veio acontecer apenas em 2005, quando passou a vigorar a Lei $\mathrm{n}^{\circ} 11.133$ de 14 de julho de 2005, que instituiu o dia 21 de setembro como dia nacional de luta das pessoas com deficiência (BRASIL, 2005).

O interesse pela educação das pessoas com deficiência no Brasil se tornou efetivo a partir de iniciativas oficiais e particulares de ideias e/ou projetos que ganharam destaque, principalmente da França e dos Estados Unidos, como, por exemplo: o Instituto dos Meninos Cegos e o Instituto dos Meninos Surdos, todos de origem francesa.

Inspirados em experiências concretizadas na Europa e Estados Unidos da América do Norte, alguns brasileiros iniciaram, já no século XIX a organização de serviços e atendimentos a cegos, surdos, deficientes intelectuais e mentais e deficientes físicos. Durante um século, tais providências caracterizaram-se como iniciativas oficiais e particulares isoladas, refletindo o interesse de alguns educadores pelo atendimento dos portadores de deficiência (MAZZOTTA, p. 16, 2005). 
A primeira escola voltada para o ensino da pessoa com deficiência no Brasil, deve-se a José Álvares de Azevedo (cego), que estudou no Instituto dos Meninos Cegos em Paris. Ele ao retornar ao Brasil criou uma escola nos moldes daquela que outrora tinha estudado e obteve êxito na educação da jovem Adélia Seguimond (que era cega também), filha do médico da família real do II Império Dr. José F. Xavier Seguimond. O Dr. Seguimond foi quem influenciou o Ministro do Império, o Conselheiro Couto Ferraz, que por sua vez logrou êxito junto ao imperador D. Pedro II, quanto à criação de uma escola aos cegos no Rio de Janeiro, sendo que em 17 de setembro de 1854 foi inaugurado o Imperial Instituto dos Meninos Cegos, atual Instituto Benjamin Constant, que apesar das dificuldades de ordem financeira, continua funcionando até os dias atuais.

De acordo com Mazzotta (2005), o objetivo do Instituto compreendia “desde o ensino básico - ensinar a ler, a escrever, matemática básica, ciências, etc... até o ofício, com o qual o jovem pudesse se desenvolver profissionalmente". Havia uma preocupação com a cultura em geral, mas o foco era o de fornecer instrumentos ao aluno com deficiência visual de modo que fosse possível ele ter uma vida com independência.

Em 1857, foi criado o Imperial Instituto dos Surdos-Mudos, atual Instituto Nacional de Educação de Surdos. Esta escola foi criada devido ao esforço de Ernesto Hul e seu irmão francês diretor do Instituto Borges, na França. Hul chegou ao Brasil na metade do século XIX, com suas credenciais, apresentou-se ao Marquês de Abrantes que o levou até o imperador D. Pedro II, que aderiu à ideia de Hul de fundar o Instituto.

Depois de cem anos, o Imperial Instituto dos Meninos Surdos-Mudos passou a se chamar Instituto Nacional de Educação de Surdos (INES). Desde o começo, o INES atendia uma população de alunos com idade entre 7 a 14 anos, sendo que o ensino era voltado para o estudo literário e profissionalizante. Dentre as atividades que os dois Institutos ofereciam aos seus estudantes tinham: Oficinas de tipografia, encadernação (para pessoas cegas) e douração (pessoas surdas), pois havia uma preocupação dos dois institutos quanto à vida profissional desses estudantes.

Apesar da iniciativa do Governo Imperial em fundar essas duas, a maioria das pessoas ficavam excluídas desse atendimento. Ainda em 1872, a título de exemplo, o Instituto Benjamim Constant atendia 35 alunos cegos, em uma população de 15.848 pessoas cegas em todo país, enquanto o Instituto Nacional de Educação de Surdos atendia 17 surdos, em uma população de 11.595 surdos em todo o Brasil. 
Em 1874 foi a vez dos deficientes intelectuais e mentais iniciarem os atendimentos médicos-pedagógicos no Hospital Estadual de Salvador/BA, atualmente chamado de Hospital Juliano Moreira. Com o avanço científico, surgiram trabalhos que subdividiram a educação de pessoas com deficiência. É possível destacar que na metade do século XX, havia 54 estabelecimentos especializados à educação de deficientes, destes, quarenta eram mantidos pelos Governo Federal e Estadual, e mais tarde pelo municipal, e os demais eram mantidos pela iniciativa privada.

No tocante à legislação educacional, a primeira vez em que a legislação brasileira se refere à educação dos alunos excepcionais, foi na Lei ${ }^{\circ}$ 4.024/61, conforme o seu "Art. 88. A educação de excepcionais, deve, no que fôr possível, enquadrar-se no sistema geral de educação, a fim de integrá-los na comunidade" (BRASIL, 1961).

$\mathrm{Na}$ década de 1970, com a visita do norte-americano James Gallagher ao Brasil, possibilitou-se a criação do Centro Nacional de Educação Especial (CENEESP), criado pelo Decreto $n^{\circ} 72.425$ (BRASIL, 1973), assinado pelo então presidente Emílio Médici, no período da Ditadura Militar. Vale ressaltar que o CENEESP mudou várias vezes de nome e chegou até ser Instituto. Porém, em 1990, este centro passou a ser a Secretaria de Educação Especial, órgão ligado ao Ministério da Educação e Cultura.

Em 1972 foi constituído pelo Ministério de Educação e Cultura - MEC o Grupo - Tarefa de Educação Especial e juntamente com o especialista James Gallagher, que veio ao Brasil a convite desse Grupo, foi apresentada a primeira proposta de estruturação da educação especial brasileira, tendo sido criado um órgão central para geri-la, sediado no próprio Ministério e denominado Centro Nacional de Educação Especial - CENESP. Esse Centro, hoje, é a Secretaria de Educação Especial - SEESP, que manteve basicamente as mesmas competências e estrutura organizacional de seu antecessor, no MEC (MANTOAN, 2004, p. 4).

Mudanças significativas só ocorrem com a CF de 1988, em que garantiu-se o acesso à educação para todos os brasileiros pelos Art. 205, 206 e 208, assim como o atendimento educacional especializado aos estudantes com deficiência, ao regulamentar que "A educação, direito de todos e dever do Estado e da família, será promovida e incentivada com a colaboração da sociedade, visando ao pleno desenvolvimento da pessoa e seu exercício para a cidadania". Enquanto que o seu Art. 206 reconhece a "[...] igualdade de acesso e permanência na escola", e mais adiante em seu artigo 208 [...] prevê que "o Atendimento 
Educacional Especializado aos portadores de deficiência, será preferencialmente na rede regular de ensino" (GOMES, 2006).

A Lei $n^{\circ} 7.853$ de 1989, no seu Art. $2^{\circ}$ estabelece que, cabe ao Ministério Público assegurar o pleno exercício dos direitos básicos às pessoas que têm alguma deficiência, definindo medidas que devem ser cumpridas pelos órgãos governamentais, direta ou indiretamente, ligados com a educação (BRASIL, 1989). A partir desse momento, a oferta da Educação Especial passou a ser obrigatória desde a pré-escola, incluindo as séries do $1^{\circ}$ e $2^{\circ}$ graus do sistema regular de ensino.

Em 1996, foi promulgada a atual Lei $n^{\circ} 9.394 / 96$, que estabeleceu que a educação é direito de todos e dever do Estado e da família, criando uma seção específica para tratar da Educação Especial, o qual é um grande avanço ao assunto, sendo que assim se refere nos Art. 58 e 59:

Art. 58 Entende-se por educação especial, para efeitos desta Lei, a modalidade de educação escolar, oferecida preferencialmente na rede regular de ensino, para educandos portadores de necessidades especiais $[\ldots] \rrbracket 1^{\circ}$ Haverá, quando necessário, serviços de apoio, especializado, na escola regular, para atender às peculiaridades da clientela da educação especial [...].

Art. 59 Os sistemas de ensino assegurarão aos educandos com necessidades especiais: I - currículos, métodos, técnicas, recursos educativos e organização específicas, para atender as suas necessidades (BRASIL, 1996).

Com a promulgação da LDBN, foi garantido o acesso e a permanência dos alunos com deficiência à matrícula na rede regular de ensino público, com a oferta de AEE em classes especiais, quando necessário. Ainda no seu Art. 59, foi reconhecida a adaptação de currículo, métodos, técnicas e a formação dos profissionais para atender esse grupo de estudantes. Fato esse, que não estava garantido em leis anteriores do país (BRASIL, 1996).

Nos últimos anos, a política nacional de promoção da pessoa com deficiência tem conquistado grandes avanços. Em 2009, o Brasil promulgou com status de Emenda Constitucional, a Convenção sobre Direitos da Pessoa com Deficiência da ONU, através do Decreto no 186/2008 e Decreto no 6.949/2009 (BRASIL, 2008; 2009).

Para efetivação desse direito, sem discriminação e com base na igualdade de oportunidades, os países membros reconheceram o sistema educacional 
inclusivo em todos os níveis, bem como o aprendizado ao longo de toda a vida, com os seguintes objetivos, segundo o seu item 2 do Art. 24:

[...] b) As pessoas com deficiência possam ter acesso ao ensino primário inclusivo, de qualidade e gratuito, e ao ensino secundário, em igualdade de condições com as demais pessoas na comunidade em que vivem; c) Adaptações razoáveis de acordo com as necessidades individuais sejam providenciadas; d) As pessoas com deficiência recebam o apoio necessário, no âmbito do sistema educacional geral, com vistas a facilitar sua efetiva educação; e) Medidas de apoio individualizadas e efetivas sejam adotadas em ambientes que maximizem o desenvolvimento acadêmico e social, de acordo com a meta de inclusão plena (BRASIL, 2009).

Um texto que trouxe polêmica sobre a pessoa com deficiência, foi o novo Plano Nacional de Educação (PNE) - Lei no 13.005 sancionada em 25 de junho de 2014, que em uma de suas metas, a de número 4, houve bastante discordância entre elementos propostos (BRASIL, 2014). Em um primeiro momento, a crise se deu devido às diferentes correntes que defendem a Educação Especial, na perspectiva inclusiva. As Associações de Pais e Amigos dos Excepcionais (APAE), por exemplo, preferem que as crianças com deficiência sejam atendidas pelas instituições especializadas, enquanto que o movimento das pessoas com deficiência defendem que lugar de estudante com deficiência é na escola e inseridos nas classes comuns e que o AEE, deve ser oferecido também pela rede regular de ensino.

Em 2011, a luta das pessoas com deficiência evidenciou-se com a promulgação do Decreto n 7.612 de 17 de novembro de 2011, que institui o Plano Viver sem Limites, o que ficou conhecido como Plano Nacional dos Direitos das Pessoas com Deficiência (BRASIL, 2011). O Plano teve por objetivo garantir o acesso da pessoa com deficiência à graduação, emprego e lazer em todos os âmbitos sociais, em igualdade de oportunidades, com as demais pessoas da sociedade.

O primeiro artigo deste decreto estabeleceu que:

Art. $1^{\circ}$ Fica instituído o Plano Nacional dos Direitos da Pessoa com Deficiência - Plano Viver sem Limite, com a finalidade de promover, por meio da integração e articulação de políticas, programas e ações, o exercício pleno e equitativo dos direitos das pessoas com deficiência, nos termos da Convenção Internacional sobre os Direitos das Pessoas com Deficiência e seu Protocolo Facultativo, aprovados por meio do Decreto 
Legislativo no 186, de 9 de julho de 2008, com status de emenda constitucional, e promulgados pelo Decreto $\mathrm{n}^{\circ}$ 6.949, de 25 de agosto de 2009 (BRASIL, 2011).

Ainda em 2011, foi promulgado o Decreto $\mathrm{n}^{\circ}$ 7.611, também de 17 de novembro do mesmo ano. Esse decreto é chamado de "o novo AEE" e dispõe sobre a Educação Especial e dá outras providências, conforme definido no seu $\$ 1^{\circ}$ do Art. $2^{\circ}$ :

Art. $2^{\mathbf{o}}$ A Educação Especial deve garantir os serviços de apoio especializado voltado a eliminar as barreiras que possam obstruir o processo de escolarização de estudantes com deficiência, transtornos globais do desenvolvimento e altas habilidades ou superdotação.

$\$ 1^{\circ}$ Para fins deste Decreto, os serviços de que trata o caput serão denominados atendimento educacional especializado, compreendido como o conjunto de atividades, recursos de acessibilidade e pedagógicos organizados institucional e continuamente [...] (BRASIL, 2011).

A legislação brasileira mais recente, que trata dos direitos das pessoas com deficiência é Lei Brasileira de Inclusão (LBI), a qual definiu e reconheceu um conjunto de obrigatoriedades que antes estavam apenas previstas em outras legislações. Um aspecto positivo da LBI é o conceito de pessoa com deficiência de acordo com a Convenção, conforme estabelecido em seu segundo artigo:

Art. $2^{\circ}$ Considera-se pessoa com deficiência aquela que tem impedimento de longo prazo de natureza física, mental, intelectual ou sensorial, o qual, em interação com uma ou mais barreiras, pode obstruir sua participação plena e efetiva na sociedade em igualdade de condições com as demais pessoas (BRASIL, 2015).

Pensando nas dificuldades que a escola enfrenta para definir as regras do atendimento educacional especializado, o Ministério da Educação (MEC) elaborou a Nota Técnica no 04/2014-MEC/SECADI/DPEE, documento que caracteriza como deve ser a oferta e os objetivos do AEE nas escolas brasileiras (BRASIL, 2014).

De acordo com a referida Nota Técnica, o AEE visa promover acessibilidade, atendendo às necessidades educacionais específicas dos estudantes, público da Educação Especial, devendo a sua oferta constar no Projeto Polí- 
tico-Pedagógico da escola, em todas as etapas e modalidades da Educação Básica, objetivando o acesso à educação escolar aos estudantes.

A referida nota desobriga a apresentação do laudo médico do estudante com deficiência que necessita de atendimento específico, é o que se destaca a seguir:

Neste liame não se pode considerar imprescindível a apresentação de laudo médico (diagnóstico clínico) por parte do aluno com deficiência, transtornos globais do desenvolvimento ou altas habilidades/superdotação, uma vez que o AEE caracteriza-se por atendimento pedagógico e não clínico. Durante o estudo de caso, primeira etapa da elaboração do Plano de AEE, se for necessário, o professor do AEE, poderá articularse com profissionais da área da saúde, tornando-se o laudo médico, neste caso, um documento anexo ao Plano de AEE. Por isso, não se trata de documento obrigatório, mas, complementar, quando a escola julgar necessário. O importante é que o direito das pessoas com deficiência à educação não poderá ser cerceado pela exigência de laudo (BRASIL, 2014, p. 3).

Portanto, o estudante com deficiência não deve sofrer nenhuma forma de exclusão ou cerceamento no desenvolver de suas potencialidades, sob alegação de deficiência e que o professor do AEE pode trabalhar em parceria, se necessário, com outros profissionais que desejem colaborar com o aprendizado dos estudantes atendidos pelo AEE.

\section{A VISÃO DE PROFESSORAS DA EDUCAÇÃO ESPECIAL SOBRE O ATENDIMENTO EDUCACIONAL ESPECIALIZADO NA EESJ}

A EESJ é situada no interior do Instituto de Administração Penitenciária do Amapá (IAPEN). Este localiza-se na Avenida Duca Serra, s/n, no Bairro Cabralzinho, em Macapá/AP. A coleta de dados ocorreu em setembro de 2017, na Coordenadoria da Penitenciária Feminino (COPEF), onde também são ofertados cursos de EJA às mulheres presas, em salas cedidas por essa Coordenadoria.

A coleta de dados foi realizada a partir de entrevista semiestruturada por meio da organização de Grupo Focal. A atividade desse grupo iniciou com uma explanação do professor Almiro Alves de Abreu, momento em que esclareceu às professoras da Educação Especial da EESJ, que o foco da pesquisa era 
saber sobre os serviços do atendimento educacional especializado e suas dificuldades no contexto do ambiente carcerário.

Para realizar o Grupo Focal, inicialmente realizamos uma breve exposição "O que é um grupo focal" para familiarizar as professoras participantes da pesquisa, com relação ao instrumento de coleta de dados desta pesquisa e seu objetivo, momento em que foi ressaltado que não existe nenhuma questão fechada, pois todos os relatos e as manifestações orais eram bem-vindas na discussão.

Esclarecemos que a exposição inicial era importante para saber que a investigação propunha-se a reunir um grupo de professoras, para falar sobre uma temática específica. Nesse caso, a aproximação de questões que envolvem a Educação Penitenciária e a Educação Especial, bem como para explicar que o grupo focal se propõe a ouvir os participantes do estudo, devendo apresentar seu ponto de vista. A possibilidade de discordar não é para promover desentendimento, mas que a pesquisa científica considera também os pontos de vistas divergentes.

Por meio da organização do grupo focal, pode-se reconstruir e criar significados, vivenciar e ressignificar questões por meio da troca de informações. Segundo Abramovay e Castro (2003, p. 47):

O grupo focal é uma técnica de entrevista na qual os membros do grupo narram e discutem visões e valores sobre eles próprios e o mundo que os rodeia. [...] A principal característica da técnica é permitir que a "palavra" de cada um dos participantes possa ser discutida pelos demais.

É importante destacar que o grupo focal é uma técnica de investigação, que visa coletar dados e promover a interação entre os participantes de um grupo.

Participaram do grupo foram 3 (três) professoras que trabalham com a Educação Especial na EESJ, sendo 2(duas) que atendem o público masculino e 1 (uma) que atende o público feminino. Para manter o anonimato das professoras, elas foram identificadas com o nome de flores: Violeta, Jasmim e Margarida.

Dando prosseguimento às atividades do Grupo Focal, perguntamos às professoras sobre sua formação e o tempo em que estavam lotadas na Educação de Jovens e Adultos na Educação Penitenciária. Constatou-se que a professora Violeta é licenciada em Pedagogia e especializou-se em Gestão e Docência 
do Ensino Superior, e trabalha na escola há 8 (oito) anos, sendo que 7 (sete) desses anos, ela trabalha na Educação Especial.

Com relação à professora Margarida, ela é licenciada em Pedagogia e trabalha há 7 (sete) anos na EESJ, com a Educação Especial. Quanto à professora Jasmim, ela é licenciada em Pedagogia e especializou-se em Educação Especial e Inclusiva. Ela trabalha há 20 (vinte) anos na Educação Especial, sendo que há 5 (cinco), ela trabalha na EESJ.

De acordo com as professoras, a Educação Especial foi implantada na EESJ, a partir de 2010, após um Projeto Piloto: Artes, Altas Habilidades e Superdotação. Após a finalização desse projeto, as professoras passaram a atender às demandas do AEE na escola, o que se confirma na fala da professora Margarida (2017):

Inicialmente não vim trabalhar exclusivamente com alunos com deficiência. A gente é levado por área de atuação e eu cheguei para fazer um trabalho de Artes sobre Altas Habilidades e Superdotação. E depois da finalização do projeto, começamos a atender as demandas das deficiências.

Dando prosseguimento ao resultado do estudo, perguntamos quantos estudantes estavam matriculados na EESJ e de que forma era realizada a sua divisão. A professora Violeta (2017) respondeu que, em média, estavam matriculados 450 estudantes. Enquanto que, a professora Jasmim respondeu que no anexo foram matriculadas 87 estudantes e que sua divisão ocorre com base na matrícula das turmas da Educação de Jovens e Adultos (EJA).

Ao perguntarmos como é realizada a matrícula escolar, a professora Violeta (2017) informou que as matrículas iniciam através da Chamada Escolar, pois os estudantes que sabem que alguém quer estudar, indicam os nomes dos interessados por meio de uma lista e também argumentou que:

A secretaria faz uma triagem, digamos que a $3^{a}$ Etapa tem 50 alunos, fora os que vão ser aprovados da $2^{\mathrm{a}}$ Etapa, as vagas remanescentes vão para um setor do Instituto o qual vai fazer o levantamento e a triagem desse aluno para saber se ele pode ou não estudar, porque tem uns alunos que não podem está na Escola por algum tipo de falta disciplinar, pena semiaberto, tem as restrições do Sistema. Quem faz a seleção final da lista que a gente manda é o IAPEN (VIOLETA, 2017). 
Em seguida foi perguntado se a EESJ oferece Educação Especial aos estudantes presos com deficiência e qual era a quantidade de atendidos. As professoras informaram que a EESJ oferece esse atendimento e que atende 7 (sete) estudantes, sendo 5 (cinco) homens e 2 (duas) mulheres. Informaram ainda que desses 7 (sete) estudantes atendidos, 5 (cinco) têm Deficiência Visual, 1 (um) Deficiência Intelectual e 1 (um) Deficiência Auditiva.

O Decreto $\mathrm{n}^{\circ}$ 5.296/2004 tipifica os diversos tipos de deficiência (BRASIL, 2004), sendo que a pessoa com Baixa Visão é caracterizada como aquela que tem um comprometimento no campo visual de ambos os olhos.

Com relação a essa deficiência visual, o referido decreto especifica que:

A baixa visão significa acuidade visual entre 0,3 e 0,5 no melhor olho com a melhor correção óptica; os casos nos quais a somatória da medida do campo visual em ambos os olhos for igual ou menor que $60^{\circ}$; ou a ocorrência simultânea de quaisquer das condições anteriores (BRASIL, 2004, p. 7).

Com relação à Deficiência Auditiva ou Surdez, segundo o referido Decreto é a "Perda bilateral, parcial ou total, de quarenta e um decibéis (dB) ou mais, aferida por audiograma nas freqüências de $500 \mathrm{~Hz}, 1.000 \mathrm{~Hz}, 2.000 \mathrm{~Hz}$ e $3.000 \mathrm{~Hz}$ ". Enquanto que, a Deficiência Intelectual, tendo por base o mencionado Decreto é caracterizada "pelo funcionamento cognitivo que não corresponde à média esperada, ou seja, que esteja abaixo do que é considerado normal" (BRASIL, 2004, p. 8).

Dando prosseguimento ao Grupo Focal, procuramos saber se existiam estudantes-presos com deficiência, que não recebem Atendimento Educacional Especializado. A professora Margarida (2017) posicionou-se em relação ao público masculino, afirmando que: "Sabemos que existem alunos que necessitam do atendimento mas não podem ser indicados devido às restrições".

Em relação ao público feminino, a professora Jasmim (2017) afirmou que: "A realidade é outra, a demanda é de cada ano. O atendimento é para todas que necessitam de apoio especializado, pois devido à demanda ser menor, dá para trabalhar".

Ao indagá-las em relação à acessibilidade arquitetônica da EESJ, as professoras responderam que não há. Elas falaram que o prédio da escola foi construído há muito tempo para ser um pavilhão para alojar presos.

A esse respeito, a professora Violeta (2017) explicou que: 
Para haver acessibilidade é necessária a construção de uma escola nova. A Escola Estadual São José não foi planejada. É uma escola que teve seus espaços implantados, gradativamente por cada gestor. Não foi uma escola pensada para alunos, é um espaço cedido pelo IAPEN, que parece um pavilhão com as paredes de concreto. Não tem uma estrutura de escola.

Com relação a esse assunto, a professora Jasmim, que trabalha com a Educação Especial na Coordenadoria da Penitenciária Feminina (COPEF), ela respondeu que: "O prédio da penitenciária feminina é um prédio moderno e que previa a existência de um espaço escolar no projeto, porém sem acessibilidade". Acrescentou que as salas de aulas também são utilizadas para cursos externos, pois o espaço pertence ao IAPEN e não à escola.

Em relação ao AEE, Jasmim (2017) falou que:

Anos atrás, as alunas recebiam o atendimento junto com os alunos na EESJ, mas devido algumas situações de envolvimento amoroso, resultou na separação do atendimento. A administração do IAPEN cedeu um espaço para a oferta do AEE, mas não foi um espaço planejado para o seu atendimento, o que vem dificultando a oferta.

De acordo com a Convenção Internacional sobre os Direitos das Pessoas com Deficiência (BRASIL, 2009), se a pessoa com deficiência cometer um crime, ela vai ser presa como as demais pessoas. No entanto, as prisões são obrigadas a oferecer às adaptações e acessibilidades, conforme determina o item 2 do Art. 14 do Decreto no 6.949/2009:

2. Os Estados Partes assegurarão que, se pessoas com deficiência forem privadas de liberdade mediante algum processo, elas, em igualdade de oportunidades com as demais pessoas, façam jus a garantias de acordo com o direito internacional dos direitos humanos e sejam tratadas em conformidade com os objetivos e princípios da presente Convenção, inclusive mediante a provisão de adaptação razoável (BRASIL, 2009).

Posteriormente, as participantes do Grupo Focal, foram indagadas sobre como identificar o aluno com deficiência. Segundo a professora Violeta (2017): "é o professor da sala de aula que identifica, seleciona os alunos que tem alguma dificuldade e encaminha às professoras do AEE". 
Também tivemos interesse em saber como acontece esse atendimento. De acordo com a professora Violeta (2017) é realizado 3 (três) vezes por semana. Ela também afirmou: "No masculino está sendo feito todos os dias em que há aula, pois devido problemas de segurança, há dias que não tem aula. Tem semana que as aulas são suspensas [...], então, passamos a dever muito, por isso ministramos aulas todos os dias para pagar os dias atrasados".

Indagadas sobre o local onde é feito esse atendimento, foi esclarecido que o atendimento é realizado numa sala adaptada da EESJ, porém sem estrutura nenhum para oferta do AEE. Em seguida, perguntamos se seria uma sala multifuncional e a professora Violeta (2017) respondeu: "Não chega nem perto de ser uma sala multifuncional, apesar de existir na escola, equipamentos como notebooks, impressora e um computador de banca, não são utilizados no espaço do AEE porque não há instalação elétrica, somente a sala com cadeiras”.

Quando perguntamos sobre a aquisição dos materiais pedagógicos utilizados pelas professoras, responderam que a escola não oferece, sendo que, elas compram com seus próprios recursos.

Já com relação ao planejamento e os atendimentos aos alunos com deficiência, elas responderam que fazem juntas para atendê-los por mais tempo. Com relação a esse assunto, a professora Jasmim (2017), que atende o público feminino, respondeu: "Meu planejamento é feito com a pedagoga e o atendimento as alunas é realizado individualmente. As alunas recebem o atendimento individual no contra turno, duas vezes na semana e meu planejamento é na sexta-feira".

Quanto às dificuldades em relação ao professor da sala de aula regular, as professoras do AEE destacaram que a maior barreira encontrada é a maneira de pensar do professor, pois a maioria acredita que o professor do AEE está para reforçar o conteúdo de sala de aula.

A professora Violeta (2017) comentou:

Acho que foi esse ano que uma professora cobrou que fizéssemos o reforço. Alguns ainda pensam que o trabalho é esse, se tem dificuldade de aprendizagem manda para a Educação Especial, mas isso aos poucos estamos vencendo, pois vamos impondo como funciona o trabalho e alguns estão compreendendo.

Outra dificuldade mencionada é a demora na entrega do planejamento dos professores da sala regular, ocasionando o atraso na confecção do material didático-pedagógico. A professora Margarida (2017) enfatizou que: “A maior 
dificuldade é a questão do material para imprimir, a demora na entrega do planejamento".

Em relação ao desenvolvimento intelectual do estudante, as professoras responderam que eles se desenvolvem bastante quando frequentam o atendimento, pois afirmam que a infrequência é constante, pois elas esperam que sejam liberados dos seus pavilhões e muitas vezes eles não são, por motivo de segurança, conforme pode-se confirmar na fala da professora Margarida (2017):

Não é a escola que chama, é a instituição que manda e se ela manda, não tem aula. Depende muito do bom senso da segurança, as vezes eles estão arrumados, mas não conseguimos convencer aquele servidor que o aluno tem que sair, apesar do nome dele está na lista. A maioria dos servidores penitenciários não vê a escola como um direito, vê como uma regalia, então o que ele puder fazer para impedir, atrapalhar, ele vai fazer.

Em relação à inserção do AEE no Projeto Político-Pedagógico (PPP) da escola, as três professoras da EESJ responderam que foi inserido. Mas o PPP, ainda está em construção e inclusive as professoras da Educação Especial fazem parte da Portaria e da Comissão designada para reformulá-lo (VIOLETA; MARGARIDA; JASMIN, 2017).

Ao indagá-las sobre a diferença na metodologia do AEE da EESJ, em relação à escola fora do cárcere (regular), elas responderam que trabalham os conteúdos através de jogos, principalmente, os jogos de concentração e que não preparam o estudante para o convívio social, pois acreditam que essa atribuição é do professor da sala de aula. É o que se confirma na fala da professora Violeta (2017): "Nosso trabalho é voltado à educação, não para o retorno ao convívio social".

É importante destacar que nas falas das professoras, percebemos as suas visões de que o ensino pode ajudar a transformar a vida das pessoas presas. Além disso, elas não se sentem responsáveis, quanto à inserção dos egressos do sistema penitenciário ao convívio social fora da prisão.

Finalizando as atividades do Grupo Focal, foi perguntado às professoras, se elas costumam falar de coisas da vida cotidiana com os estudantes-presos com deficiência, como: futebol, política, novela e outros assuntos.

A professora Margarida (2017) disse que:

Se deixar eles falam, todos os atendimentos eles sempre tem uma situação e se reportam. Falam o que viram na televisão, falam dos conflitos, se a gente deixar eles utilizam o momento para falar de uma situação que 
estão passando, falam de suas dificuldades, descrevem até o motivo porque estão ali. Tem a parte psicológica, eles querem contar “ah, eu não fiz isso, mas isso me levou a fazer isso" e muitas vezes a gente até corta para não entrar nesses méritos.

Depreende-se a partir dos relatos das professoras, que para terem sucesso na tarefa de ensinar, os profissionais da educação que trabalham na escola em contexto de confinamento, devem dominar os saberes, relacionando-os à vida cotidiana por meio de valores democráticos e a realidade carcerária.

\section{CONCLUSÃO DO ESTUDO}

A partir dos resultados obtidos por meio do Grupo Focal foi possível constatar que a EESJ não está preparada tanto pedagógica, como arquitetonicamente para receber o estudante preso com deficiência visual (DV), auditiva (DA) e intelectual (DI). De acordo com os relatos das professoras que participaram deste estudo, evidenciou-se que elas não têm autonomia para desenvolver seu trabalho da Educação Especial na Educação Penitenciária. Além disso, na escola não tem sala multifuncional e os equipamentos existentes não são usados por falta de instalação elétrica, o que foi percebido durante a coleta de dados da pesquisa.

Assim, a EESJ não tem um espaço adequado para atender às demandas educacionais, tampouco para realizar os serviços do AEE. O corpo docente enfrenta na sua rotina de trabalho, dificuldades para continuar promovendo a formação escolar aos adultos presos, considerando que os problemas da escola pública se manifestam de forma ressignificadas na Educação de Jovens e Adultos na Educação Penitenciária.

Por mais vontade que as professoras da Educação Especial tenham, em desenvolver com qualidade o seu trabalho como servidoras públicas, elas defrontam-se com barreiras arquitetônicas e pedagógicas semanalmente, que se tornam quase intransponíveis. Por outro lado, evidenciou-se a vontade por parte das professoras do AEE de desenvolver o seu trabalho. Porém, falta de infraestrutura na EESJ, aliada à ineficiência do poder público em efetivar os serviços do AEE no contexto de encarceramento, o que impede que as professoras realizem um atendimento de qualidade aos adultos presos, com deficiência visual (DV), auditiva (DA) e intelectual (DI).

Há de se considerar que os direitos das pessoas privadas de liberdade foram reconhecidos em leis, decretos, resoluções e documentos internacionais. 
No cotidiano da educação penitenciária, pouco foi implementado em relação aos serviços do AEE, no Estado do Amapá. Fato que nos leva a pensar sobre: Como tornar o apenado uma pessoa melhor, se são tratados de maneira tão desumana?

O resultado do estudo proporciona refletir, que há muitas demandas recorrentes da Educação de Jovens e Adultos no contexto da Educação Penitenciária para serem discutidas e planejadas como pautas, que devem ser inseridas no "Plano de Educação para o Sistema Penitenciário amapaense" (AMAPÁ, 2014), e que necessitam ser formuladas as sua metas, visando atender à realidade escolar-prisional, principalmente, quanto ao atendimento educacional especializado aos estudantes no ambiente carcerário.

Assim, se o direito de punir deve ser cumprido no Estado do Amapá, não se pode esquecer que a oferta de cursos de Ensino Fundamental e Médio aos estudantes da EESJ também deve, por ser a educação um direito social e humano. Os cursos da EJA na educação penitenciária devem possibilitar o acesso aos conhecimentos necessários aos adultos presos. Além de garantir o acesso aos serviços educacionais, que tem direito as pessoas com deficiência e que são estudantes da EESJ, para diminuir as barreiras pedagógicas e arquitetônicas na execução dos serviços do AEE.

\section{REFERÊNCIAS}

ABRAMOVAY, M.; CASTRO, M. G. (Coord.). Ensino médio: múltiplas vozes. Brasília: UNESCO, MEC, 2003.

ABREU, A. A. Educação entre grades: um estudo sobre a educação penitenciária do Amapá. 2008. Dissertação (Mestrado em Educação) - Universidade Federal de São Carlos, São Carlos, 2008.

\section{AMAPÁ. Plano Estadual de Educação para o Sistema Penitenciário} Amapaense. Macapá, 2014.

ARGENTINA. Ley de Educación Nacional. Disponível em: < $\underline{\text { http://www.i- }}$ net.edu.ar/index.php/institucional/normativa/ley-de-educacion-nacional/> . Acesso: 10/12/2018.

BRASIL. Constituição Política do Império do Brasil de 25 de março de 1824. In: NOGUEIRA, O. Constituições Brasileiras. 3.ed. Brasília: Senado Federal, Subsecretaria de Edições Técnicas, 2012. p. 65-88. Vol. 1. 
Lei $\mathrm{n}^{\circ} 4.024$ de 20 de dezembro de 1961. Fixa as diretrizes e bases da educação nacional. Diário Oficial da União, Brasília, 27 de dezembro de 1961.

. Lei n ${ }^{\circ} 7210 / 84$. Institui a Lei de Execução Penal. In: GOMES, L. F.

(Org.). Constituição Federal, Código Penal, Código de Processo Penal.

8.ed. São Paulo: RT, 2006. Vol. 2.

A Lei n ${ }^{\circ} 7.853$ de 24 de outubro de 1989. Dispõe sobre o apoio às

pessoas portadoras de deficiência, sua integração social, sobre a Coordenadoria

Nacional para Integração da Pessoa Portadora de Deficiência - Corde, institui a tutela jurisdicional de intereresses coletivos ou difusos dessas pessoas, disciplina a atuação do Ministério Público, define crimes e dá outras providências. Diário Oficial da União, Brasília, 25 de outubro de 1989.

. Lei n ${ }^{\circ}$ 9394/96 de 20 de dezembro de 1996. Estabelece as diretrizes e

bases da educação nacional. Diário Oficial da União, Brasília, 23 de dezembro de 1996.

. Decreto $n^{\circ} 6.571$ de 17 de setembro de 2008. Dispõe sobre o atendimento educacional especializado, regulamento o parágrafo único do Art. 60 da Lei $\mathrm{n}^{\circ} 9.394$ de 20 de dezembro de 1996, e acrescenta dispositivo ao Decreto $n^{\circ}$ 6.253, de 13 de Novembro de 2007. Diário Oficial da União, Brasília, 18 de setembro de 2008 .

. Decreto no 6.949, de 26 de Agosto de 2009. Promulga a Convenção Internacional sobre os Direitos das Pessoas com Deficiência e seu Protocolo Facultativo, assinados em Nova York, em 30 de março de 2007. Diário Oficial da União, Brasília, 26 de agosto de 2009.

Resolução $\mathbf{n}^{\circ} \mathbf{4}$ de 2 de outubro de 2009. Institui diretrizes operacionais para o atendimento educacional especializado na educação básica, modalidade educação especial. Disponível em: < www.portal.mec.gov.br> $>$. Acesso em : 10 dez. 2018.

. Decreto Federal no 7.611 de 17 de Novembro de 2011. Dispõe sobre a educação especial, o atendimento educacional especializado e dá outras providências. Diário Oficial da União, Brasília, 18 de novembro de 2011.

. Decreto Federal no 7.612, de 17 de Novembro de 2011. Institui o Plano Nacional dos Direitos da Pessoa com Deficiência-Plano Viver sem Limite. Diário Oficial da União, Brasília, 18 de novembro de 2011. 


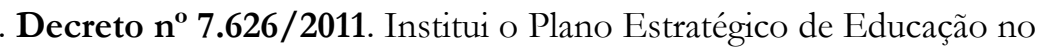
âmbito do sistema prisional. Disponível em:

$<$ http://portal.mec.gov.br/index.php? option $=$ com content\&view $=$ article\&id $=17460 \&$ Itemid $=817,>$ Acesso em 10 dez. 2018.

Lei $\mathbf{n}^{\circ} \mathbf{1 3 . 0 0 5}$ de 25 de junho de 2014. Aprova o Plano Nacional de Educação - PNE e dá outras providências. Disponível em: < $\underline{\text { http://www.pla- }}$ nalto.gov.br/ccivil 03/Ato2011-2014/2014/Lei/L13005.htm>Acesso em: 10 dez. 2018.

. Lei $\mathbf{n}^{\circ} \mathbf{1 3 . 1 6 3}$ de 9 de setembro de 2015. Modifica a Lei no ${ }^{\circ} .210$ de 11 de julho de 1984 - Lei de Execução Penal, para instituir o ensino médio nas penitenciárias. Disponível em: http://www.planalto.gov.br/ccivil_03/ Ato2015-2018/2015/Lei/L13163.htm, Acesso em : 10 dez. 2018.

. Nota Técnica n ${ }^{\circ}$ 04/2014-MEC/SECADI/DPEE. Trata da orientação quanto aos documentos comprobatórios de alunos com deficiência, transtornos globais do desenvolvimento e altas habilidades/superdotação no Censo Escolar. Disponível em: < http://www.portal.mec.gov.br>Acesso em: $10 \mathrm{dez}$. 2018. . Lei no 13.146, 6 de Julho de 2015. Institui a Lei Brasileira de Inclusão da Pessoa com Deficiência. Diário Oficial da União, Brasília, 07 de julho de 2015.

DROPA. R. F. Direitos humanos no Brasil: a exclusão dos detentos, 2001. Disponível em: < http://www.advogado.adv.br/artigos/2003 >. Acesso em: 10 dez. 2018.

FOUCAULT, M. Vigiar e Punir: Nascimento da prisão. Trad. Raquel Ramalhete. Petrópolis: Vozes, 2013.

GOMES, L. F. (Org.). Constituição Federal, Código Penal, Código de Processo Penal. 8.ed. São Paulo: RT, 2006. Vol. 2.

MANTOAN, M. T. E. Inclusão escolar: O que é? Por que? Como fazer? São Paulo: Moderna, 2004.

MAZZOTTA, M. A Educação Especial no Brasil: História e políticas públicas. 5.ed. São Paulo: Cortez, 2005. 
MESSEMER, J. E. The Historical Practice of Correctional Education in the United States: a review of the literature. International Journal of Humanities and Social Science, Roseville, Vol. 1, n. 17, Special Issue, Nov. 2011.

VASQUEZ, E. L. Sociedade cativa. Entre cultura escolar e cultura prisional: uma incursão pela ciência penitenciária. 2.ed. rev. Rio de Janeiro: Câmara Brasileira de Jovens Escritores, 2015. 